\title{
THE ROLE OF STRUCTURAL TRANSFORMATION IN THE POTENTIAL OF ASIAN ECONOMIC GROWTH
}

Neil Foster-McGregor and Bart Verspagen

NO. 479

March 2016
ADB ECONOMICS WORKING PAPER SERIES 
ADB Economics Working Paper Series

\section{The Role of Structural Transformation in the Potential of Asian Economic Growth}

Neil Foster-McGregor and Bart Verspagen

No. 479 | March 2016
Neil Foster-McGregor (foster@merit.unu.edu) is research fellow at UNU-Merit and Bart Verspagen (verspagen@merit.unu.edu) is director of UNU-MERIT and director-dean of the Maastricht Graduate School of Governance at Maastrict University.

This was a background paper for the Asian Development Outlook 2016 theme chapter on Asia's Potential Growth. 
Asian Development Bank

6 ADB Avenue, Mandaluyong City

1550 Metro Manila, Philippines

www.adb.org

(C) 2016 by Asian Development Bank

March 2016

ISSN 2313-6537 (Print), 2313-6545 (e-ISSN)

Publication Stock No. WPS167938-2

The views expressed in this paper are those of the authors and do not necessarily reflect the views and policies of the Asian Development Bank (ADB) or its Board of Governors or the governments they represent.

ADB does not guarantee the accuracy of the data included in this publication and accepts no responsibility for any consequence of their use.

By making any designation of or reference to a particular territory or geographic area, or by using the term "country" in this document, $A D B$ does not intend to make any judgments as to the legal or other status of any territory or area.

Note: In this publication, "\$” refers to US dollars.

The ADB Economics Working Paper Series is a forum for stimulating discussion and eliciting feedback on ongoing and recently completed research and policy studies undertaken by the Asian Development Bank (ADB) staff, consultants, or resource persons. The series deals with key economic and development problems, particularly those facing the Asia and Pacific region; as well as conceptual, analytical, or methodological issues relating to project/program economic analysis, and statistical data and measurement. The series aims to enhance the knowledge on Asia's development and policy challenges; strengthen analytical rigor and quality of ADB's country partnership strategies, and its subregional and country operations; and improve the quality and availability of statistical data and development indicators for monitoring development effectiveness.

The ADB Economics Working Paper Series is a quick-disseminating, informal publication whose titles could subsequently be revised for publication as articles in professional journals or chapters in books. The series is maintained by the Economic Research and Regional Cooperation Department. 


\section{CONTENTS}

FIGURES

ABSTRACT

$\begin{array}{ll}\text { I. INTRODUCTION } & 1\end{array}$

II. STRUCTURAL TRANSFORMATION IN THE GLOBAL ECONOMY 2

III. POTENTIAL LABOR PRODUCTIVITY GROWTH IN ASIA 3

IV. $\quad$ DECOMPOSING PRODUCTIVITY GROWTH 9

V. THE ROLE OF STRUCTURAL TRANSFORMATION:

A COUNTERFACTUAL ANALYSIS

VI. CONCLUSION AND DISCUSSION 22

$\begin{array}{lr}\text { REFERENCES } & 25\end{array}$ 


\section{FIGURES}

$1 \quad$ Employment Shares for Growing Income Levels

2 Potential and Actual Growth Rates of Labor Productivity

3 Contributions of Potential Labor Productivity Growth $\left(\hat{y}^{N}\right)$

and Filtered Labor Force Growth $\left(\hat{n}^{N}\right)$ to Potential Output Growth $\left(\hat{g}^{N}\right)$,

22 Asian Economies, 2000-2007 and 2008-2013

4 Contributions of the Change in Potential Labor Productivity Growth and of the

Change in Filtered Labor Force Growth to the Change in Potential Output Growth,

22 Asian Economies, 2000-2007 and 2008-2013

$5 \quad$ Structural Decomposition of Labor Productivity Growth, 1990-2011

6 Sectoral Decomposition of Labor Productivity Growth, 1990-2011 12

$7 \quad$ Structural Decomposition of Potential Labor Productivity Growth, 1990-2011 13

8 Decomposition of TFP Growth, 1995-2009 15

9 Potential Labor Productivity Growth and TFP Growth, 1995-2009 16

10 The Employment Structure of High-, Middle- and Low-Income Reference Economies 18

11 Sectors' Employment Shares, Asian Countries and Reference Structures 19

12 Counterfactual Labor Productivity Growth and Structural Change, 1986-2011, Relative to Country's Actual Experience, Middle-Income Reference 20

13 Counterfactual Labor Productivity Growth and Structural Change, 1986-2011, Relative to Country's Actual Experience, High-Income Reference 


\begin{abstract}
The transition from low-income developing country to high-income developed country involves a deep process of structural transformation in which the productive structure of an economy changes. In this paper we examine this process of structural change and its link to productivity growth for a sample of Asian countries. In particular, the paper addresses the following questions: What is the typical pattern of structural change that countries experience when they catch up from low-income levels to the economic frontier?; To what extent and in which form did structural change contribute to productivity growth in Asia since 1990?; How does the contribution of structural change to productivity growth compare to the effects of deviations of actual growth from potential growth?; How does the effect of structural change differ between total factor productivity growth and labor productivity growth?; And, what is the order of magnitude of the productivity effects that can be expected from further convergence of Asian countries to the economic structure that characterizes middle-income and high-income countries?
\end{abstract}

Keywords: labor productivity, structural decomposition, total factor productivity

JEL codes: $\mathrm{O} 14, \mathrm{O} 47$ 


\section{INTRODUCTION}

Rich countries produce, consume, and invest entirely different goods and services than poor countries. Those (few) countries that managed to make the transition from low-income developing country to high-income developed country have gone through a deep process of structural transformation in which the productive structure of their economy was changed completely. Most recent examples of this type of country are found in Asia. The so-called Asian Tigers (the Republic of Korea; Taipei,China; Singapore; Hong Kong, China) were the first generation of postwar developing countries that managed to make the transition from developing to developed. More recently, other Asian countries, including recently the People's Republic of China (PRC), have entered on this road with high growth periods and rapid structural change.

This paper implements an empirical analysis of the role of structural change in Asian growth over the past 3 decades, and draws from this analysis to provide an assessment of the role of structural change in the future potential of Asian growth and development. The paper implements two distinct but complementary decomposition techniques to identify the impact of different forms of structural change on productivity growth (both labor productivity and total factor productivity).

The analysis in this paper proceeds along four main stages. We start, in section II, by providing a broad picture of the relationship between structural change and economic growth. In this part of the analysis, we provide a stylized picture of how the employment shares of nine main sectors evolve with increasing average income in the economy. This analysis is based on a broad global sample of countries for the period 1950-2011, including many developing countries. The outcome of the analysis provides evidence for the role of industrialization and deindustrialization in the development process, as well as for the rise of the role of services.

In the second stage of the analysis, in section III, we provide evidence on the evolution of the potential rate of labor productivity growth in Asia in the period since 1990. We investigate whether growth potential in Asia has declined or increased in a sample of Asian countries, and to what degree that potential has been exploited. The time series for potential growth that are derived in this section are the basis for further empirical analysis.

Section IV provides a third stage of the analysis, by linking the potential growth paths of section III to the patterns of structural change of section II. Here the question of the role that structural change plays is addressed, and the historical role that individual sectors played historically in Asian economic growth since 1990. We show that changes in the employment shares of sectors played a large role in most Asian countries. We also illustrate the traditionally leading role of the manufacturing sector, and the impact of the process of deindustrialization that took place since the 1990s.

The final stage of the analysis, in section $\mathrm{V}$, undertakes a counterfactual analysis in which the three main development stages of section II are linked to the historical growth paths of Asian countries. The counterfactual analysis asks how growth would be influenced if the countries in our analysis would converge to either a typical middle-income employment structure, or a high-income structure. The purpose of this analysis is not to predict what will happen, but rather to provide a rough idea of the order of magnitude of the effect of structural change on growth that is associated with the structural transformation that countries can undergo when they manage to catch up to the global technological and economic frontier. 


\section{STRUCTURAL TRANSFORMATION IN THE GLOBAL ECONOMY}

We start the analysis by providing a broad overview of structural transformation in the global economy over a long period. In order to do this, we utilize data from the Groningen Growth and Development Centre (GGDC) 10-sector database, ' on employment shares in the economies of 42 countries, in combination with data on gross domestic product (GDP) per capita (taken from the Maddison project database) for the same economies. ${ }^{2}$ The 10 sectors of the database are aggregated into nine sectors, by adding up public sector services and social and community services. Our analysis is aimed at detecting the patterns of change in the employment shares of the sectors, when income levels grow.

The analysis is undertaken for the period 1950-2011, although we do not have data for all countries for the entire period. We undertake a so-called lowess (locally weighted scatterplot smoothing) regression in order to reconstruct the typical pattern of structural transformation in the 42 economies. This method estimates a relationship between the employment share of each of the sectors and GDP per capita, on a moving local band of GDP per capita levels. Thus we obtain a smooth, nonparametric relationship between GDP per capita levels and the employment structure of the economy that is representative for the sample of 42 countries.

The results from this method are akin to the early work of Chenery (1960), amongst others, who attempted to detect the typical pattern of structural change along the path of so-called modern economic growth (Kuznets 1971). The results are displayed in Figure 1. The most clear aspect of structural transformation that is visible in these results is the decline of agriculture in employment when income (GDP per capita) progresses. At levels of GDP per capita below $\$ 5,000$, which roughly corresponds to the borderline between low- and middle-income countries, agriculture is the dominating sector in the economy. In low-income countries, it is typically responsible for $80 \%$ or more of total employment.

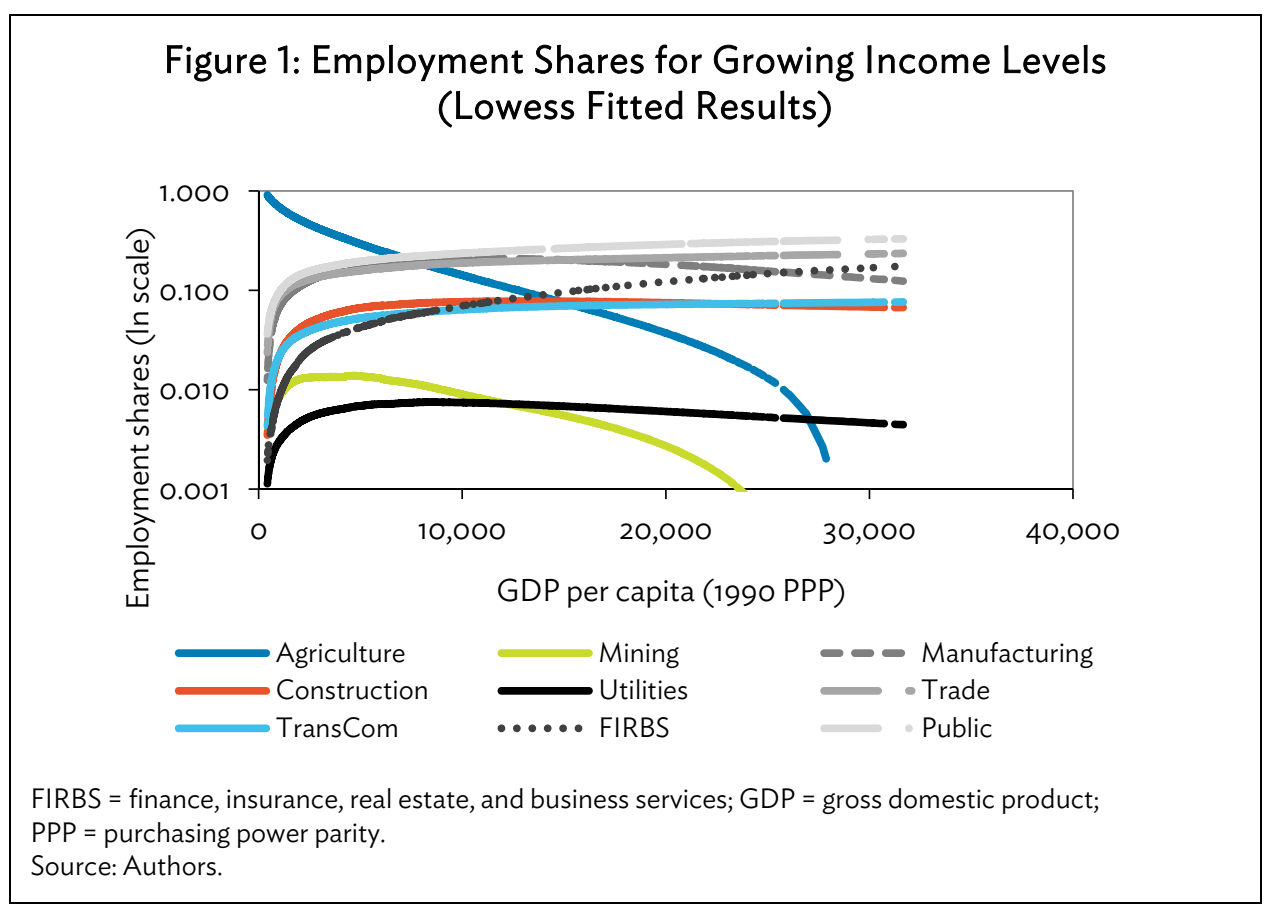

http://www.rug.nl/research/ggdc/data/10-sector-database

2 http://www.ggdc.net/maddison/maddison-project/data.htm 
When the share of agriculture falls, that of all other sectors tends to increase. These other sectors can be roughly divided into three groups, according to the share that they attain in the transition from low income to middle income. In the first group are manufacturing; trade (wholesale and retail, and including restaurants and hotels); and the public sector. These sectors grow rapidly when the share of agriculture decreases, and quickly reach employment shares above $10 \%$. The second group consists of construction, transport and communication, and finance, insurance, real estate, and business services (FIRBS). These generally do not exceed the $10 \%$ level when the economy reaches middle-income levels. The final group consists of mining, and public utilities, which do see rising shares but typically remain very small sectors (below or only slightly above $1 \%$ employment share).

With the transition from middle income to high income, another major structural change takes place. The share of the manufacturing sector declines (it reaches a peak around $\$ 12,000$ on the horizontal axis), while the share of the FIRBS sector keeps increasing. Ultimately, at about $\$ 25,000$, the share of the FIRBS sector surpasses that of manufacturing. Thus, we may conclude that, in very broad terms, the transition from a low-income economy to a high-income economy is a process in which the economy turns from agricultural-based to service-based. The manufacturing sector plays a transitory role, with its importance reaching a peak at the middle-income stage. It is this process of structural transformation that we will investigate below in much more detail, with a focus on growth and transformation in Asia.

\section{POTENTIAL LABOR PRODUCTIVITY GROWTH IN ASIA}

We start the detailed investigation of Asian economic growth by looking at the potential growth rates of labor productivity in Asia, over the past decades. These results are based on the analysis in a companion background paper (Lanzafame et al. forthcoming), which focuses on estimating potential GDP growth in Asia. The potential growth rate is defined as the maximum growth rate that can be obtained without raising inflationary pressure in the economy, and is estimated using an aggregate demand and supply model.

We use the growth rates of potential output growth, and subtract the (smoothed) growth rate of the labor force, to obtain the growth rate of potential labor productivity. As an indicator of the labor force, we use the population aged 16-65. This is done because labor market data are not entirely reliable for many Asian countries (and emerging economies in general), so we proxy the labor force growth with data on working-age population growth, duly filtered to purge short-term variability (e.g., due to transitory migration flows) and obtain a better estimate of potential (long-term) labor force growth. The results are displayed in Figure 2. We see a steadily declining trend in Taipei,China, and a drop in the average rate of potential growth in the Republic of Korea after 2000 . Other than this, there is no strong evidence of a secular decline in potential labor productivity growth rates in Asia, although associated with the recent crisis, a downward trend is visible in the two largest countries in terms of population (PRC and India). Only in the PRC and the Philippines is there a structural deviation between the potential rate and the actual rate of labor productivity growth. In the PRC, the actual rate is usually above the potential rate, while in the Philippines it is usually the reverse. In all other countries, the actual rate fluctuates around the potential rate. 
Figure 2: Potential and Actual Growth Rates of Labor Productivity
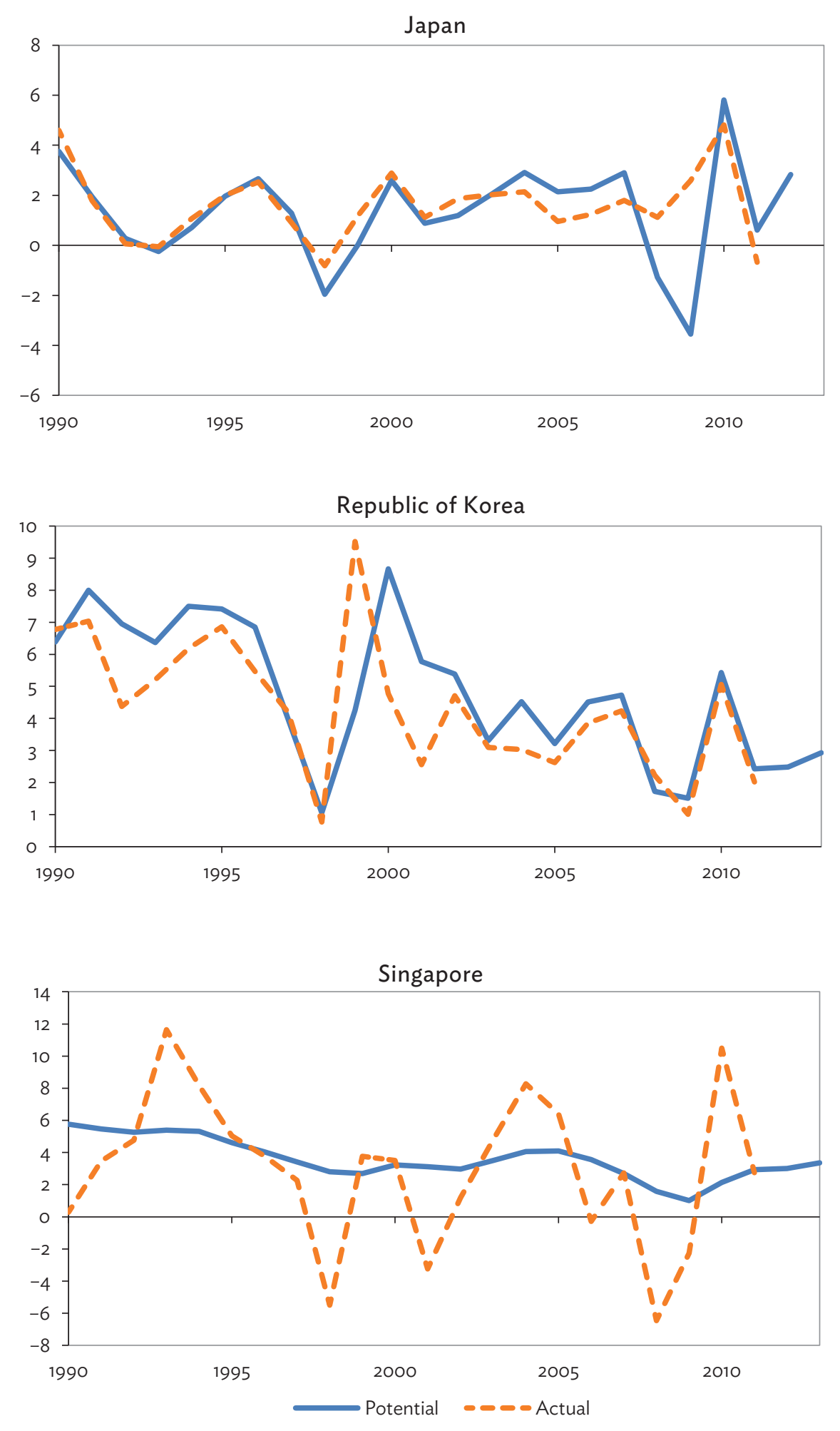

continued on next page 
Figure 2 continued

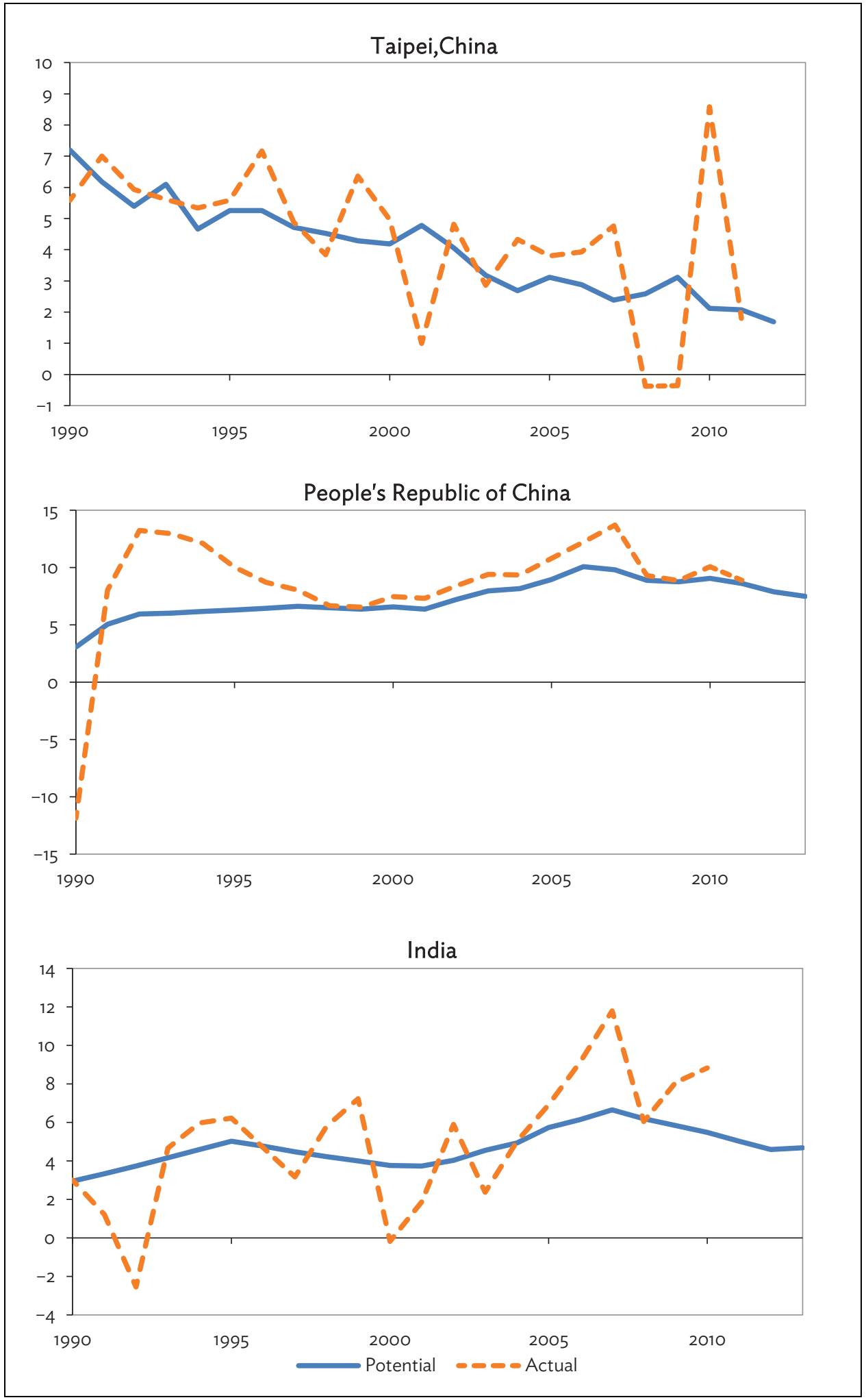

continued on next page 
6 | ADB Economics Working Paper Series No. 479

Figure 2 continued

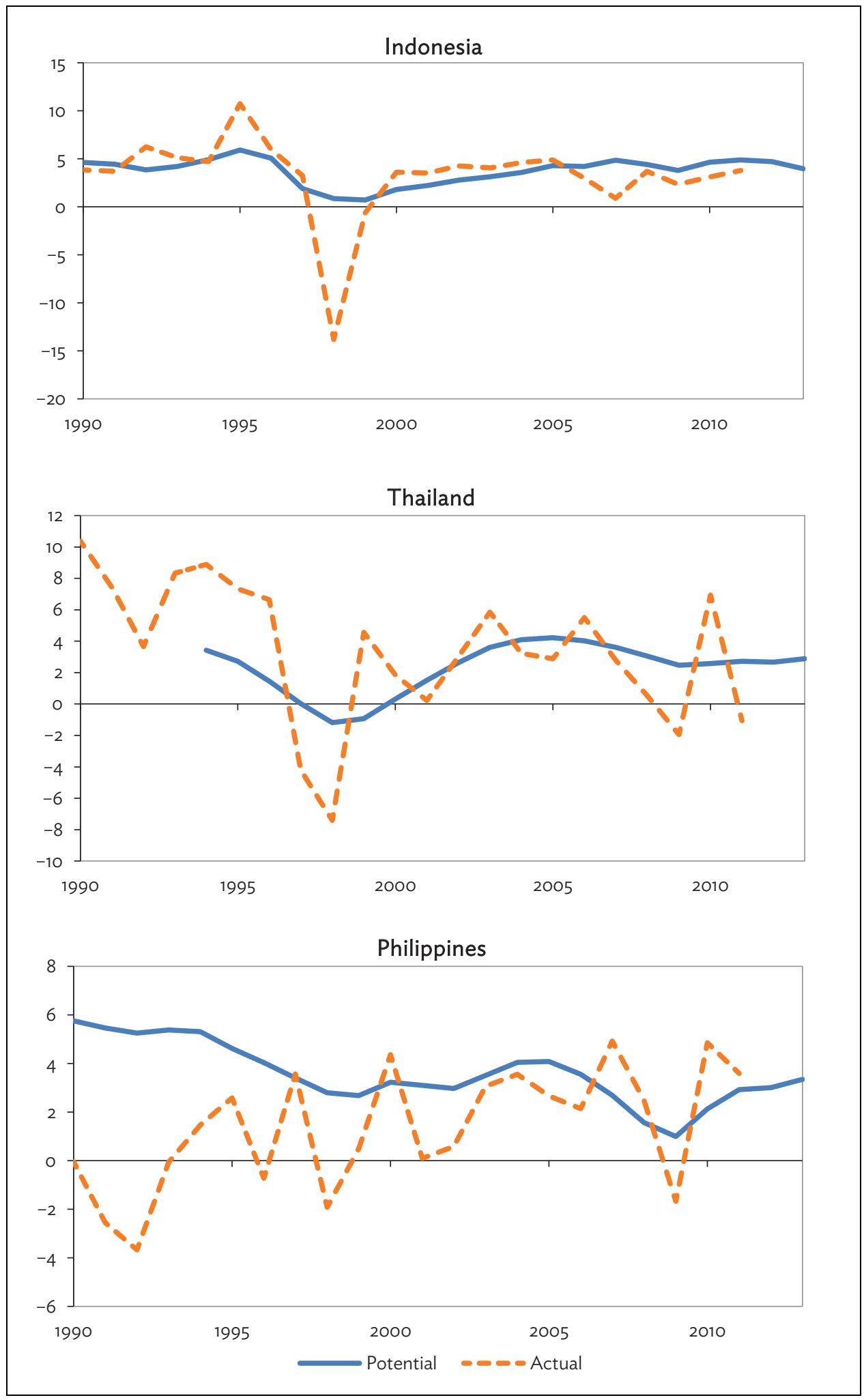

continued on next page 
Figure 2 continued

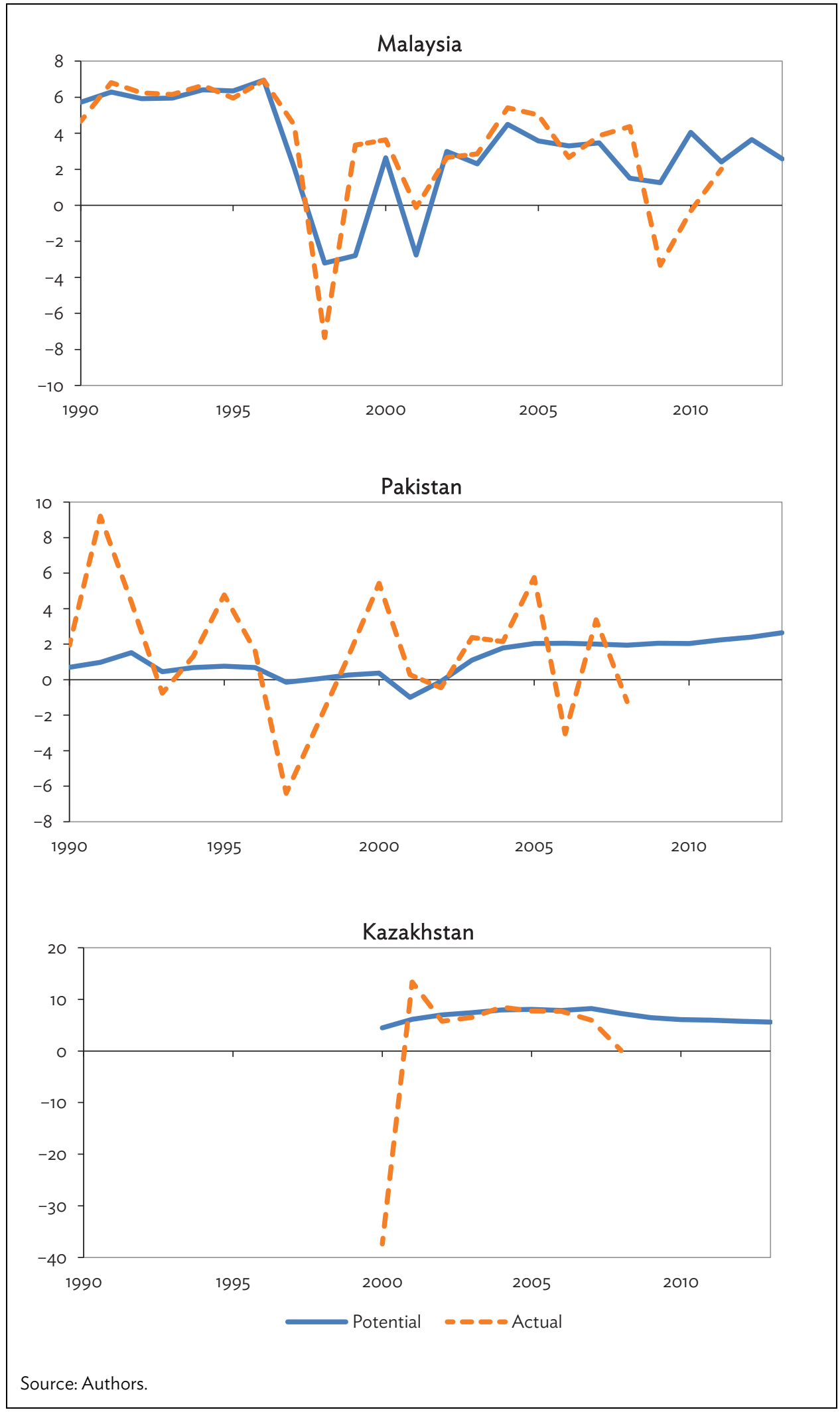


In Figure 3, we report the respective contributions of potential labor productivity growth and filtered labor force growth to potential output growth in 2000-2007 and 2008-2013, thus comparing the crisis period with the precrisis period. The figure shows that, with a few exceptions (Malaysia, Pakistan, Singapore), potential labor productivity growth is the main contributor to potential output growth in virtually all cases. Using the simple unweighted average, potential labor productivity growth accounted for about $71 \%$ of potential output growth during 2000-2007, as well as during 2008-2013.

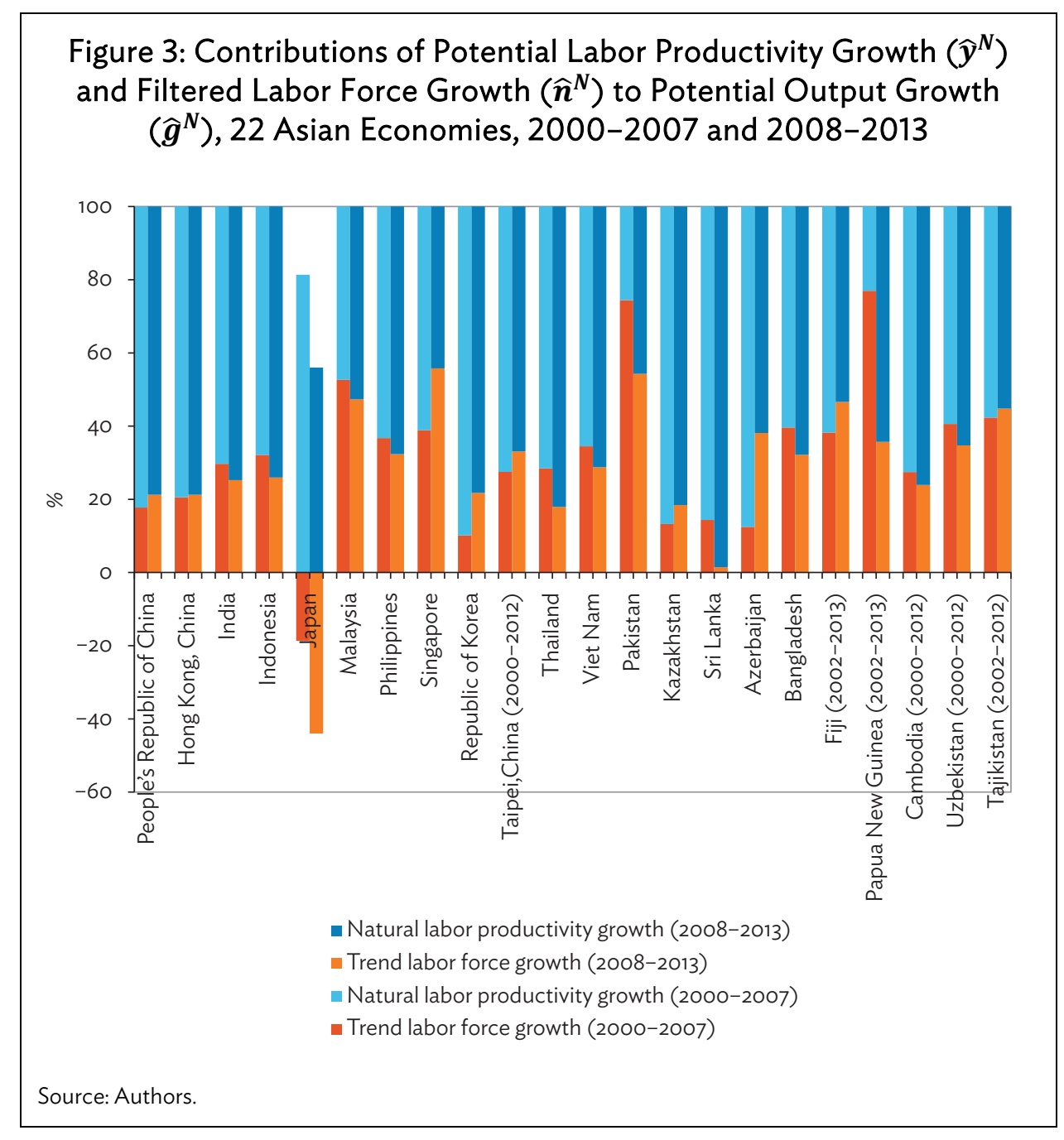

Figure 4 shows the change in annual average potential output growth rates (decline in most cases) between 2000-2007 and 2008-2013 (solid line, right axis). The figure further shows the relative contributions of potential labor productivity growth and of filtered labor force growth (left axis). Overall, using the simple unweigthed average, the decline in potential labor productivity growth accounted for $69.1 \%$ of the decline in potential output growth between 2000-2007 and 2008-2013. 


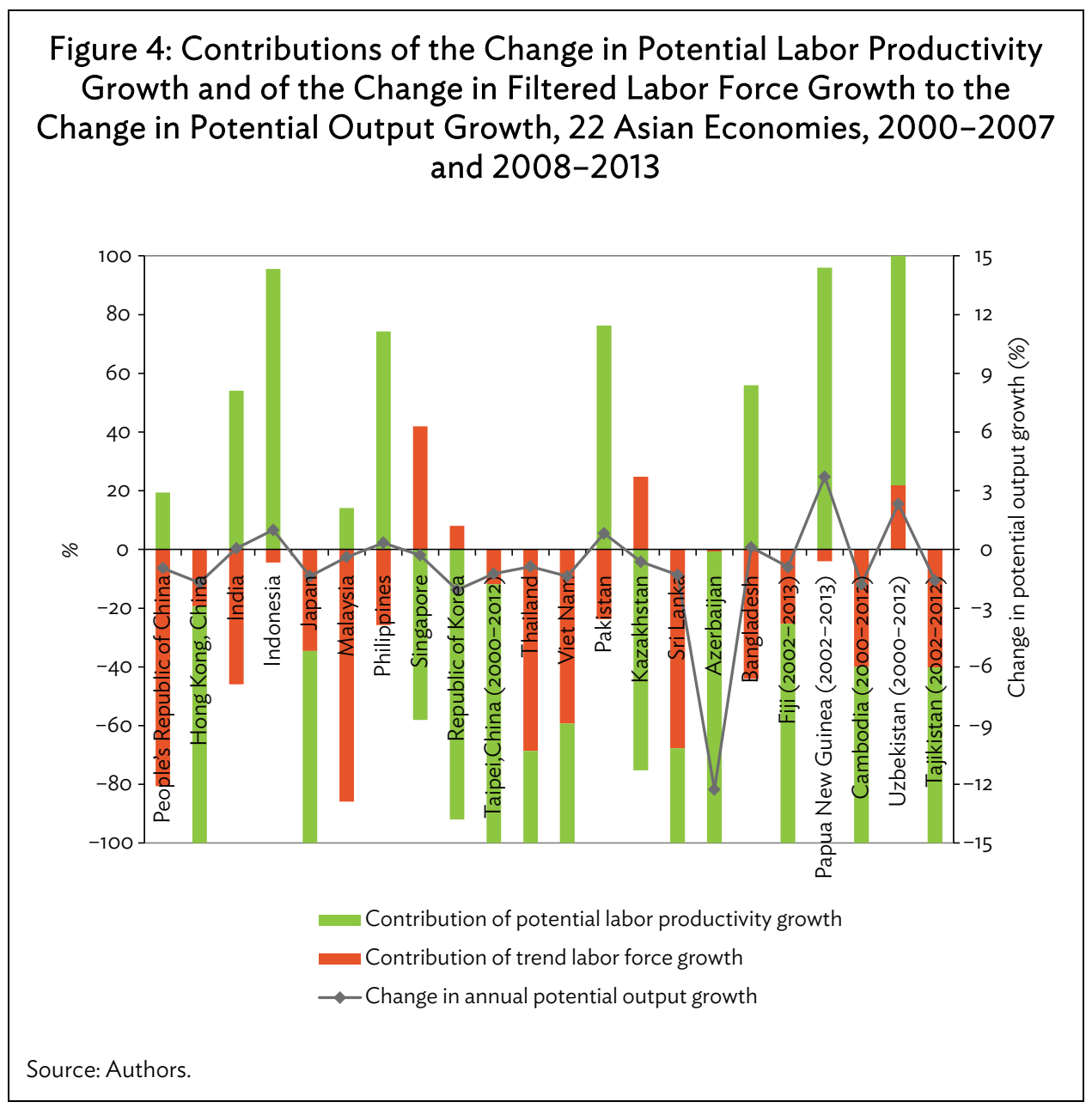

\section{DECOMPOSING PRODUCTIVITY GROWTH}

In this section we follow and extend some recent studies (e.g., McMillan, Rodrik, and Verduzci-Gallo 2014) that decompose measures of productivity into within-industry and sectoral reallocation effects. In particular, we implement decompositions of labor productivity growth, potential labor productivity growth, and total factor productivity (TFP) growth to discuss the dynamics of growth in Asia. Each of these decompositions links labor productivity growth to changes in the structure of the economy.

We begin by decomposing labor productivity growth into three factors: within, which measures the contribution of productivity growth rates within each sector; static, which measures the productivity effect of relocating labor that results from differences in productivity levels at the start of the period; and dynamic, which measures the productivity effect of relocating labor that results from differences in productivity growth rates over the period. The key idea is that relocating resources (employment) across sectors will affect aggregate productivity. The last two effects capture this. We then extend this decomposition to TFP growth and to potential labor productivity growth. The starting point for our analysis is the well-known structural decomposition of labor productivity growth given by (omitting the subscript ' $t$ ' for time): 


$$
\hat{g}-\hat{l} \equiv \hat{y}=\sum_{i} \frac{\left(y_{i}^{1}-y_{i}^{0}\right)}{y^{0}} S_{i}^{0}+\sum_{i} \frac{\left(s_{i}^{1}-S_{i}^{0}\right)}{y^{0}} y_{i}^{0}+\sum_{i} \frac{\left(y_{i}^{1}-y_{i}^{0}\right)\left(s_{i}^{1}-S_{i}^{0}\right)}{y^{0}}
$$

where $\hat{g}$ is the growth rate of GDP, $\hat{l}$ is the growth rate of aggregate labor input, $y$ is labor productivity, $\hat{y}$ denotes labor productivity growth, and $S_{i}$ denotes the share of industry $i$ in aggregate employment. The effects on the right-hand side are, respectively, (i) the within effect (contribution of productivity growth rates within each sector), (ii) the static effect (measures the productivity effect of relocating labor that results from differences in productivity levels at the start of the period), and (iii) the dynamic effect (measures the productivity effect of relocating labor that results from differences in productivity growth rates over the period). The sum of the last two adds up to the total effect of employment reallocation.

This structural decomposition of labor productivity growth is applied also to the potential rate of labor productivity growth $\left(\hat{y}^{N}\right)$, by rewriting the definition of potential growth rate $\left(\hat{g}^{N}\right)$ as follows:

$$
\hat{y}^{N} \equiv \hat{g}^{N}-\hat{n}^{N}=(\hat{g}-\hat{l})-\left(\hat{g}-\hat{g}^{N}\right)+\left(\hat{l}-\hat{n}^{N}\right),
$$

where $\hat{n}^{N}$ is the growth rate of potential labor force. ${ }^{3}$ As before, $(\hat{g}-\hat{l}) \equiv \hat{y}$ is the growth rate of actual labor productivity; $\left(\hat{g}-\hat{g}^{N}\right)$ is the difference between the actual rate of output growth and the potential rate, or output gap. Finally, $\left(\hat{l}-\hat{n}^{N}\right)$ is the difference between actual employment growth and the growth rate of the potential labor force, and equal to the growth rate of the activity rate (defined as employment divided by the labor force). We call this the labor gap. These last two terms reflect 'slack' due to the economy not being at potential.

Substituting Equation (1) into Equation (2) gives rise to a decomposition of potential labor productivity growth:

$$
\hat{y}^{N}=\sum_{i} \frac{\left(y_{i}^{1}-y_{i}^{0}\right)}{y^{0}} S_{i}^{0}+\sum_{i} \frac{\left(s_{i}^{1}-S_{i}^{0}\right)}{y^{0}} y_{i}^{0}+\sum_{i} \frac{\left(y_{i}^{1}-y_{i}^{0}\right)\left(s_{i}^{1}-S_{i}^{0}\right)}{y^{0}}-\left(\hat{g}-\hat{g}^{N}\right)+\left(\hat{l}-\hat{n}^{N}\right)
$$

A similar decomposition can be used to split labor productivity growth into TFP growth, a measure of efficiency, and capital deepening. To do this, we first decompose TFP growth into the same three terms as above for labor productivity growth. This will allow us to examine whether the growth rates of labor productivity and of efficiency gains are driven by the same factors. To achieve this, we replace labor productivity in Equation (1) with TFP $(\phi)$, which gives the following decomposition:

$$
\hat{\phi}=\sum_{i} \frac{\left(\phi_{i}^{1}-\phi_{i}^{0}\right)}{\phi^{0}} S_{i}^{0}+\sum_{i} \frac{\left(S_{i}^{1}-S_{i}^{0}\right)}{\phi^{0}} \phi_{i}^{0}+\sum_{i} \frac{\left(\phi_{i}^{1}-\phi_{i}^{0}\right)\left(S_{i}^{1}-S_{i}^{0}\right)}{\phi^{0}}
$$

Here we have the same three terms as in Equation (1) capturing the within, static, and dynamic contributions to, in this case, TFP growth $(\hat{\phi})$.

Finally, we combine the TFP growth decomposition with the decomposition of potential labor productivity growth to arrive at a more detailed decomposition of the latter by accounting for both capital deepening and TFP growth. To do this, note that we can write actual labor productivity growth in terms of TFP growth as:

$$
(\hat{g}-\hat{l})=\hat{\phi}+(1-\alpha)(\hat{k}-\hat{l})
$$

3 Potential labor force growth is the result of applying the Corbae-Ouliaris filter to the actual labor force series. 
where $\hat{k}$ is the growth rate of aggregate capital, and $(1-\alpha)$ is the share of capital in GDP (assuming perfectly competitive factor markers). This equation states that the growth rate of actual labor productivity is equal to TFP growth plus the weighted growth rate of the capital-labor ratio, with the weight being the share of capital in GDP. Replacing $\hat{\phi}$ in Equation (5) with the expression in Equation (4) and inserting this into Equation (2) results in the following decomposition of potential labor productivity growth:

$\hat{y}^{N}=\sum_{i} \frac{\left(\phi_{i}^{1}-\phi_{i}^{0}\right)}{\phi^{0}} S_{i}^{0}+\sum_{i} \frac{\left(S_{i}^{1}-S_{i}^{0}\right)}{\phi^{0}} \phi_{i}^{0}+\sum_{i} \frac{\left(\phi_{i}^{1}-\phi_{i}^{0}\right)\left(S_{i}^{1}-S_{i}^{0}\right)}{\phi^{0}}+(1-\alpha)(\hat{k}-\hat{l})-\left(\hat{g}-\hat{g}^{N}\right)+\left(\hat{l}-\hat{n}^{N}\right)$

which relates potential labor productivity growth to the within, static, and dynamic contributions to TFP growth, capital deepening, and the output and labor gaps.

Results from the structural decomposition of labor productivity growth (Equation (1)) are reported in Figure 5 for 17 Asian countries for 1990-2011. These are the Asian economies for which we have reasonably good data, even though for some of these countries data is not available for the entire period (this is indicated on the horizontal axis labels). Countries are ordered (from left to right) in ascending order of average potential labor productivity growth rates, with average actual labor productivity growth indicated by the black line in the graph. This figure shows several important results. Firstly, the within effect dominates in most cases. Secondly, the static structural effect is also large in some countries. In Thailand, Sri Lanka, Bangladesh, and Viet Nam, it is the largest of the three effects. Finally, the dynamic structural effect is usually negative, and when it is positive it is usually small. The major exception is the PRC, where the dynamic structural effect is positive and accounts for about one-fifth of total growth.

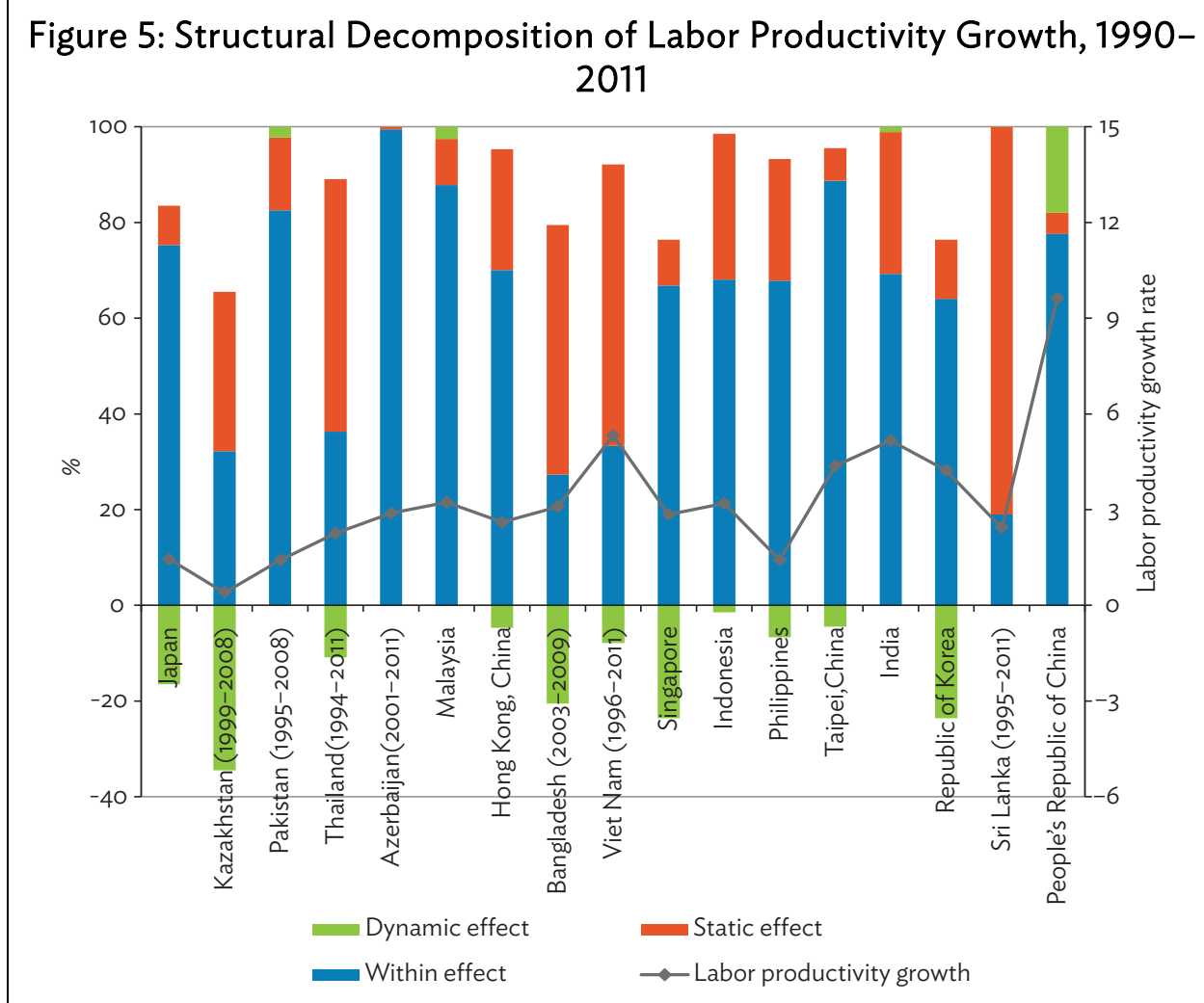

Source: Authors. 
This method can also illustrate the role of the individual sectors in labor productivity growth. Figure 6 shows the decomposition of overall labor productivity growth in terms of contributing sectors. The two sectors with the largest contribution to labor productivity growth are manufacturing and FIRBS. The contribution of manufacturing is significant in Thailand, Singapore, Indonesia, Malaysia, Bangladesh, Viet Nam, the Republic of Korea, and the PRC, while the contribution of FIRBS is significant in Hong Kong, China and Singapore. The mining sector's contribution to labor productivity growth is large in Kazakhstan and Azerbaijan. Services sectors such as trade, transport and communication; and the public sector also contribute significantly to labor productivity growth in most countries. With the exception of Pakistan, agriculture's contribution to labor productivity growth is very small.

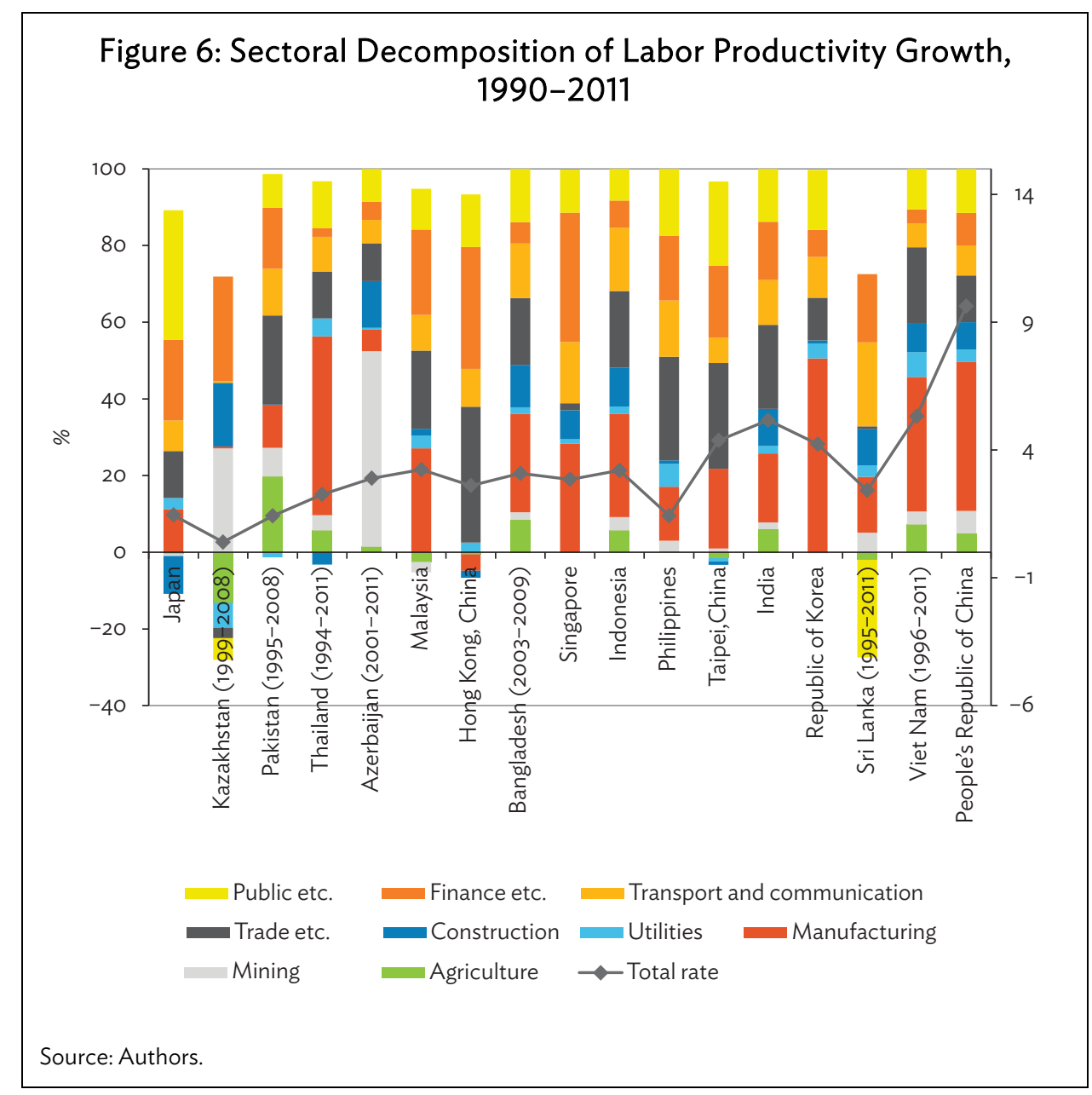

What lies behind the importance of manufacturing and FIRBS? The contribution of the manufacturing sector to overall labor productivity growth is mainly through the within effect, which means that this sector's labor productivity growth is higher than that of other sectors. At the same time, the static and dynamic effects of manufacturing are negative in countries with a significant within effect. This means that these countries are deindustrializing, i.e., the share of employment in manufacturing is declining. It is clear that deindustrialization slows down labor productivity growth in the high-income Asian countries. The within, static and dynamic effects contribute to the high labor productivity growth of FIRBS. This means that its employment is increasing, and the sector has a 
relatively high productivity level and growth rate. The same holds for the other two market service sectors, trade and transport and communications sectors. This means that Asia's growth during 19902011 has been, to an important extent, services based.

We now link the structural decomposition of labor productivity growth to our estimates of the growth rate of potential labor productivity and add two additional effects to three considered above (see Equation (3) above), namely: (i) the difference between the actual and the potential rate of output growth, i.e. the output gap, which is commonly used as an indicator of the business cycle and enters with a negative sign in the decomposition; and (ii) the difference between employment growth and the growth rate of the labor force, which we call the labor gap, and which is equal to the growth rate of the activity rate (defined as employment divided by the labor force). Combined, these two gaps are indicators of how far actual labor productivity growth is from its potential, and as such are summed up in the analysis described below.

This decomposition of potential labor productivity growth enables us to compare the importance of changes in the two gaps with the three effects in the structural decomposition discussed above. Results are displayed in Figure 7 which replicates the results of Figure 5 above (but now in terms of absolute values of the separate effects rather than their shares) and adds the combined contribution of the two gaps. Figure 7 also reports the average potential labor productivity growth for 1990-2011.

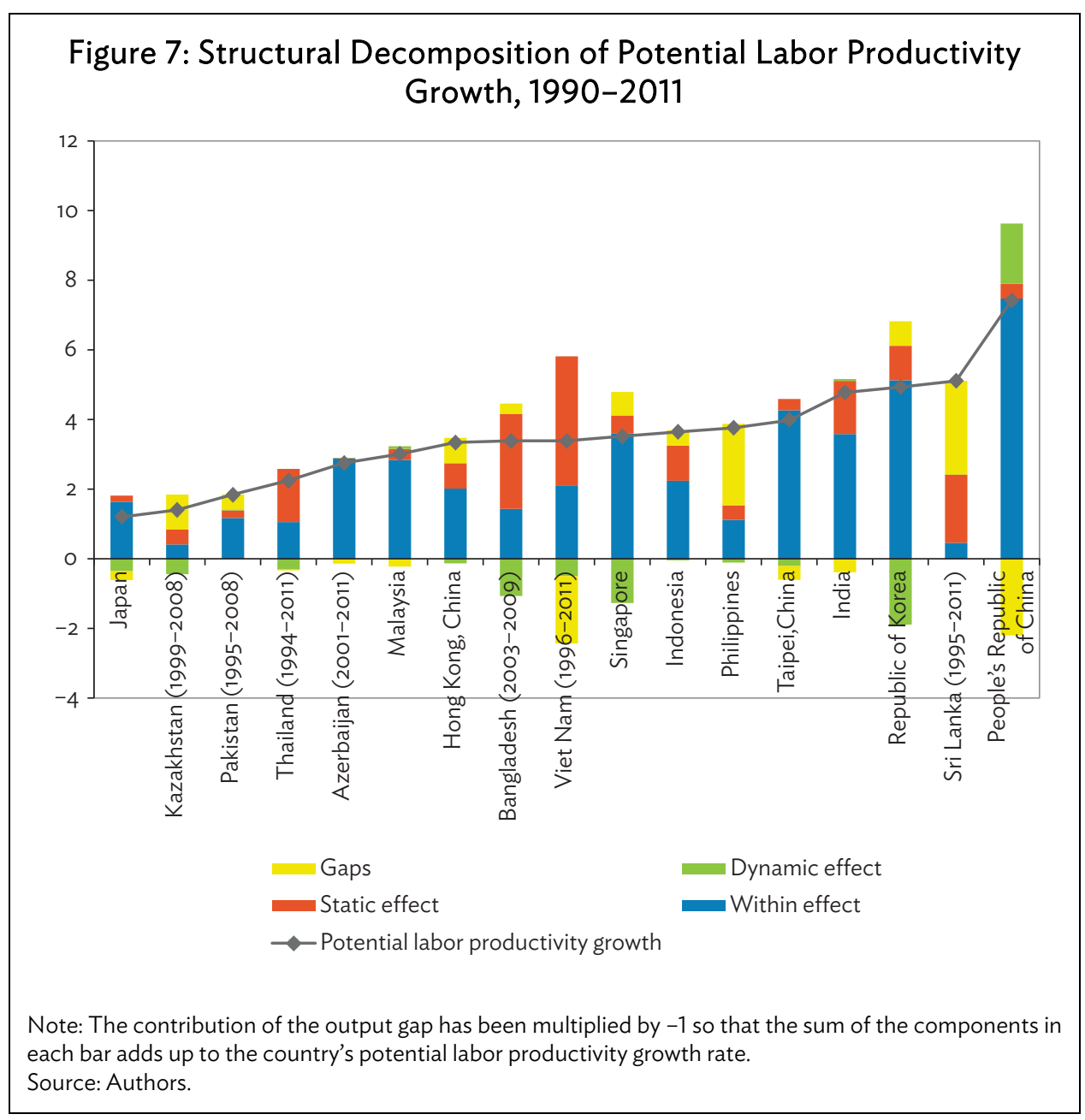


In most economies, the contribution to potential labor productivity growth of the combined gaps is relatively small compared to those of the structural effects. Kazakhstan and Sri Lanka are the two main exceptions, both with a positive contribution of the gaps (the labor gap dominates in these two cases). Such a positive contribution means that potential labor productivity growth has grown faster than actual labor productivity.

The analysis above leads us to conclude that the within productivity effect accounts for most of the positive contribution to potential labor productivity growth in most cases, $72 \%$ using the simple unweighted average, while the static effect accounts for $28 \%$, the dynamic effect is negative and small, and the contribution of the two gaps is often negative but small. ${ }^{4}$ From this it can be concluded that the nonrealization of potential plays a relatively small role in explaining potential labor productivity growth.

We now move on to the third decomposition, that of TFP growth (Equations [4] and [6] above). The World Input-Output Database (WIOD) has the necessary data to estimate TFP growth at the sectoral level. ${ }^{5}$ This database contains data for six Asian countries (PRC; India; Indonesia; Taipei,China; Republic of Korea; and Japan) and 34 non-Asian countries. It contains data for 35 sectors and covers the period 1995-2009. To make the analysis of TFP growth rates more consistent with the analysis of labor productivity growth discussed above we aggregate up the 35 sectors of the WIOD into nine sectors.

Results of the initial decomposition given by Equation (4) are shown in Figure 8. Besides the six Asian countries, we report for reference the results for some groups of non-Asian countries. These groups are the developed countries (the old members of the European Union [EU], Australia, United States, Canada); EU new member states (these are formerly communist nations in East and Central Europe); and developing and emerging non-Asian countries. The solid line shows the TFP growth rate, with countries and country groupings ranked by rates of TFP growth.

Figure 8 shows that TFP growth in the PRC, the Republic of Korea, and India have exceeded the rates observed in other regions of the world, including the relatively fast-growing European transition countries. TFP growth rates in Taipei,China and Japan are considerably lower than in the other Asian economies, though slightly higher than those observed in other non-Asian developed countries. The growth rate of TFP of Indonesia is not significantly higher than those reported for Taipei,China and Japan, a somewhat surprising finding given its distance from the technological frontier and potential for catch-up.

Consistent with the results from the labor productivity growth decomposition, Figure 8 shows that the largest positive effect on TFP growth comes also from the within component, $88 \%$ using the simple unweighted average (the static effect accounts for $17 \%$ on average and the dynamic effect share is $-5 \%$ ). This effect plays an extremely important role in explaining TFP growth in the PRC, the Republic of Korea, and Indonesia, where it contributes more than $90 \%$ of the overall growth of TFP. The case of the PRC is particularly interesting, since the contributions of the other two components are very small. The only other country group that has such a large contribution of the within component is the non-Asian developed country group. In the case of India the within component accounts for around $72 \%$ of the overall growth of TFP, similar to that of the new EU member states;

\footnotetext{
4 This means that aactual output growth is larger than potential output growth, and potential labor force growth is larger than actual labor force growth.

5 http://www.wiod.org/new_site/home.htm
} 
while the contributions of the within component of between $50 \%$ and $60 \%$ observed in the case of Taipei,China and Japan are similar to those observed in the non-Asian developing countries.

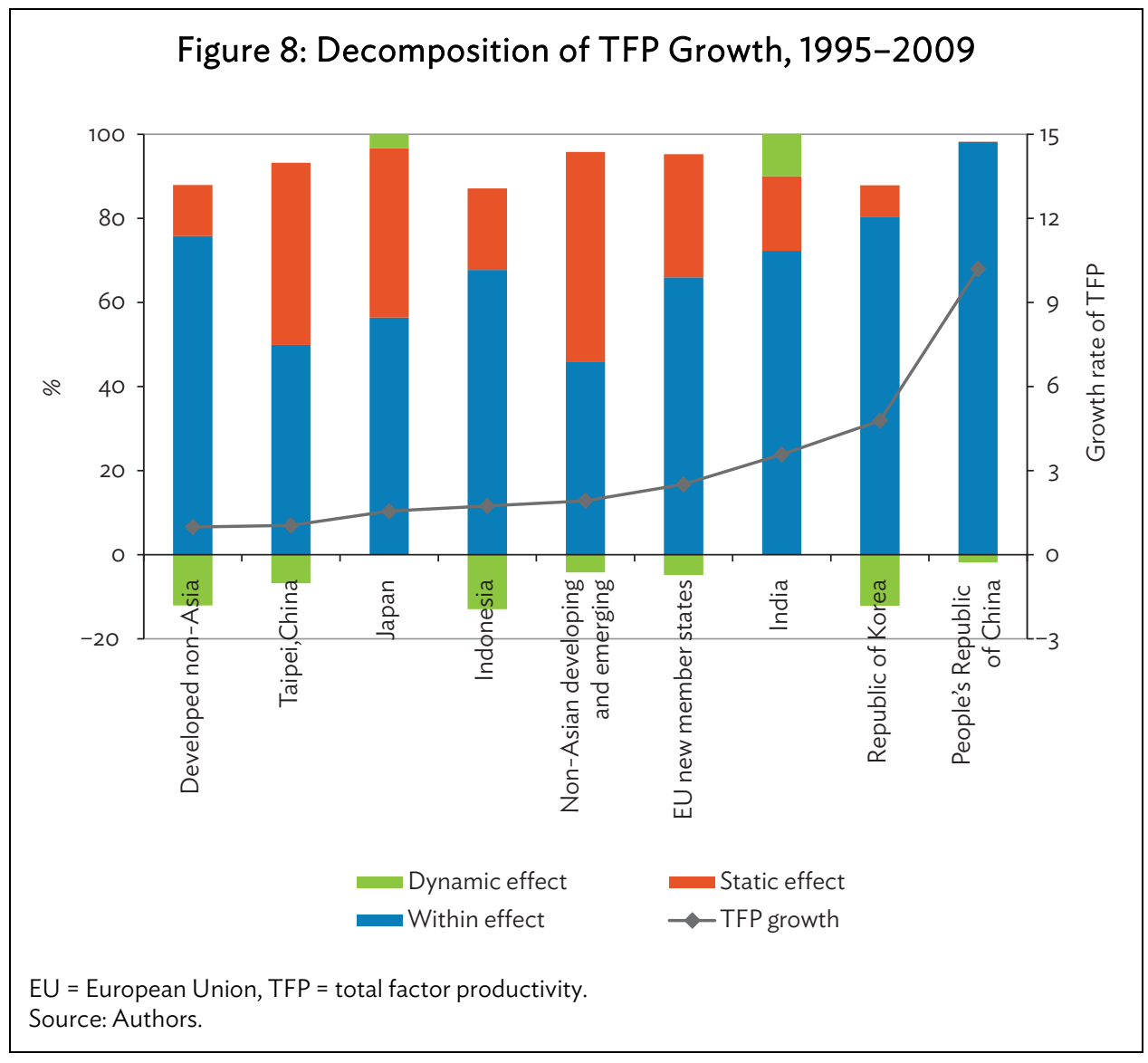

The static component is found to be positive in all countries and country groups (though very small in the case of the PRC), suggesting that there has been a movement towards sectors with initially relatively high TFP levels across the sample. The contributions of the static component are found to be relatively large for Taipei,China and Japan (over $40 \%$ of overall TFP growth) and relatively small (i.e., less than 10\% of overall TFP growth) in the PRC and the Republic of Korea. Consistent with the results for labor productivity growth, the dynamic structural effect of TFP growth is negative in most cases, the exceptions being Japan and India. Even in these two cases, however, the contribution of the dynamic structural effect is small, accounting for $3 \%$ and $10 \%$ of overall TFP growth in Japan and India, respectively. The negative effects of dynamic structural change also tend to be relatively small, being largest for Indonesia and the Republic of Korea, where the negative contribution accounts for around $17 \%$ of overall TFP growth. These dynamic effects are mostly the result of deindustrialization.

Finally, Figure 9 reports the results of the extended decomposition of potential labor productivity growth linking it with TFP growth given by Equation (6) above. In this figure we concentrate on the results for the six Asian economies reported in the WIOD database. The first thing to note is that the contribution of the capital deepening term is always positive. This implies that actual labor productivity growth is in all cases higher than TFP growth, and that a significant portion of overall labor productivity growth is due to capital deepening rather than to pure efficiency improvements (Equation (5) above). The relative importance of capital deepening is found to be particularly large for 
Taipei,China, where it accounts for more than $60 \%$ of overall potential labor productivity growth; as well as for Japan and India, where capital deepening accounts for over $40 \%$ of overall potential labor productivity growth. While the within effect is still found to make the dominant contribution to potential labor productivity growth, its relative importance diminishes in a number of cases, most notably India and Taipei,China, where the share of capital deepening is large. Consistent with the results above, the contribution of the gap terms tends to be negative, with the exceptions of Indonesia and the Republic of Korea. In the case of Indonesia the gap makes a relatively large contribution, accounting for over $30 \%$ of overall potential labor productivity growth. Such a result implies that, in these two cases, potential labor productivity has grown faster than actual labor productivity. The negative contribution of the two gaps tends to be fairly muted, with the exception of Japan, where the negative contribution is equal to around $50 \%$ of overall potential labor productivity growth. Overall, for the six countries in Figure 9, TFP growth accounted for around 74\% of potential labor productivity growth, with the within component dominating for all countries, and the dynamic component often being negative.

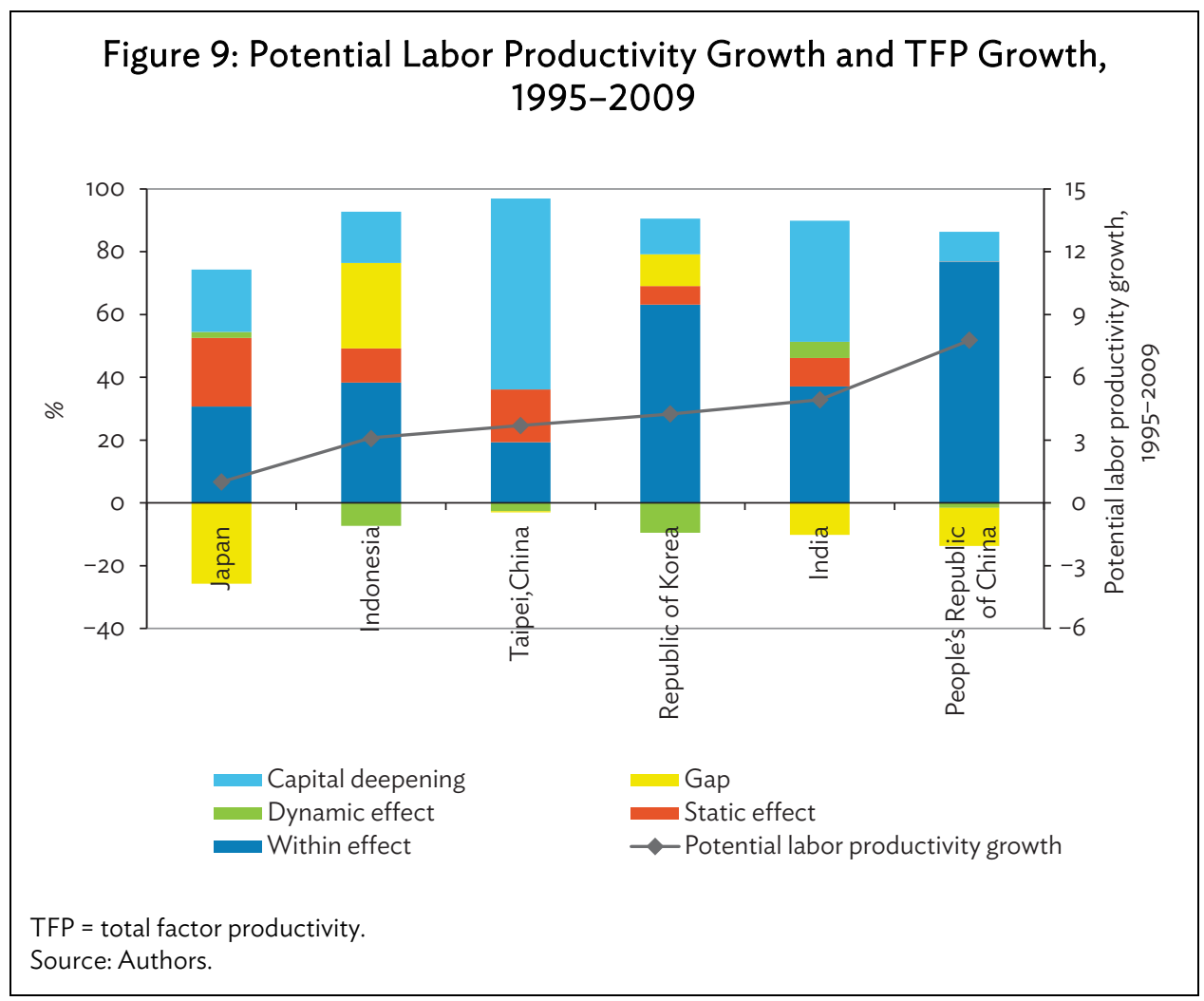

\section{THE ROLE OF STRUCTURAL TRANSFORMATION: A COUNTERFACTUAL ANALYSIS}

The analysis above has established that the role of structural change in Asian economic growth has been large over the past 25 years or so. It has also been shown that the process of deindustrialization and the rise of the services economy had a large impact on labor productivity growth. On the one hand, deindustrialization had a negative impact because the manufacturing sector still has above average labor productivity levels, meaning that a move of labor out of this sector will affect labor productivity negatively. 
On the other hand, the market services sectors to which labor moves also have relatively high productivity levels, and growth rates, so that a positive structural effect of the service economy can be shown.

At the root of our argument is the idea that these processes of deindustrialization and a larger role of the services sector are typical of the growth path that all economies follow when they manage to make the transition from low income to middle income, and ultimately to high income. This implies that structural change will continue to play a large role in Asian economic growth, as developing Asian nations move into middle-income or even high-income levels. What is the magnitude of the structural change effects that we can expect to be associated with this process of structural change along the development trajectory, and how much structural change is necessary for the Asian developing countries to achieve this? These are the questions that will be asked in this last substantial section.

In order to answer these questions, a counterfactual analysis is performed, in which we compare a country's actual labor productivity growth rate, and the actual degree of structural change, to a hypothetical growth path in which a country's employment structure would have changed to become equal to that of a reference country. Thus, the only thing that is changed in the counterfactual experiment is the employment structure at the end of the period (i.e., 2011 or the most recent year). All other variables that influence the country's growth experience, in particular the employment structure in the start year, and the growth rates of labor productivity in the sectors, are unchanged. The aim of this counterfactual is to provide a rough idea of the order of magnitude of the growth effect, and the necessary extra structural change, that would accompany the process of structural change when the country under analysis converges to the typical reference country employment structure. The purpose is not to provide a prediction, or to provide a full general equilibrium analysis of the effects of relocating employment resources.

Figure 10 shows the employment structures that are used in the counterfactual analysis. These are derived from the lowess regressions reported in Figure 1, and are simply the predicted values of these regressions at three distinct values of GDP per capita $(\$ 24,189$, the 2011 value for Taipei, China as the high-income reference; $\$ 8,737$, the 2011 value for the PRC as the middle-income level; and $\$ 3,372$, the 2010 value for India as the low-income level). ${ }^{6}$

As can be recalled from the discussion of Figure 1, agriculture is the dominating sector in the low-income economy. In the low-income reference, it accounts for $39 \%$ of employment. Public services (17\%), manufacturing (15\%), and trade (14\%) are the other large sectors in this reference country. In the middle-income reference, the share of agriculture declined strongly to $17 \%$. The share of all the other sectors rises relative to the low-income reference, with the exception of mining. In the high-income reference, the shares of agriculture and manufacturing fall relative to the middle-income reference. The share of the market services sectors keeps rising, and so does public services.

\footnotetext{
6 Note that we do not use the employment structure of these countries, but instead used the predicted values for the
} employment structure in the lowess regression at these GDP per capita levels. 
Figure 10: The Employment Structure of High-, Middle- and LowIncome Reference Economies

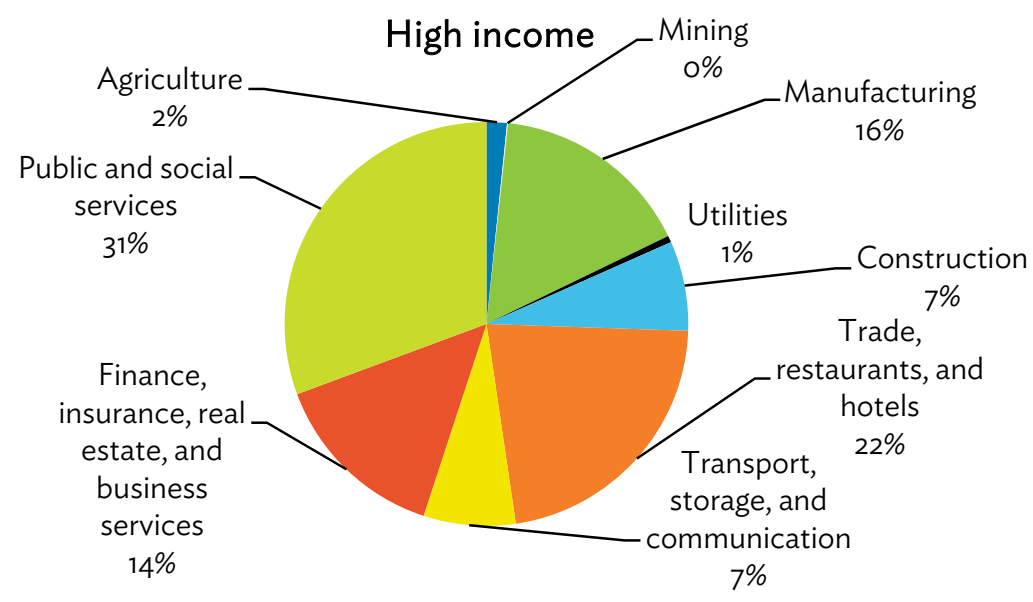

\section{Middle income}

Finance, insurance, real estate, and

Public and socia

business

services $6 \%$

Transport, storage, and communication $6 \%$

$$
\text { Trade, }
$$
restaurants, and hotels $18 \%$
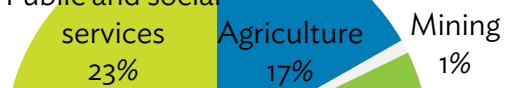

Finance, insurance, real estate, and business services $3 \%$

Transport, storage, and communication

Trade, restaurants, and $4 \%$

hotels $14 \%$

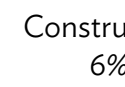

$6 \%$

\section{Low income}

Manufacturing $20 \%$ Utilities Construction $1 \%$ $8 \%$ 
For comparison purposes, Figure 11 shows the sectors' employment shares in the last year for which we have data, together with the hypothetical high and middle-income employment structures discussed above. The countries are ranked from left to right on the basis of how close they are to the high-income structure. Japan, on the left, is closest to that structure, while India is the furthest away. One very striking feature in this graph is the difference in the share of agriculture, for which there is a marked difference between economies with a relatively low share (Japan; Republic of Korea; Malaysia; Taipei,China; Hong Kong, China; and Singapore) and those with a much higher share, all others, and especially Bangladesh, Pakistan, Viet Nam and India (above 40\%).

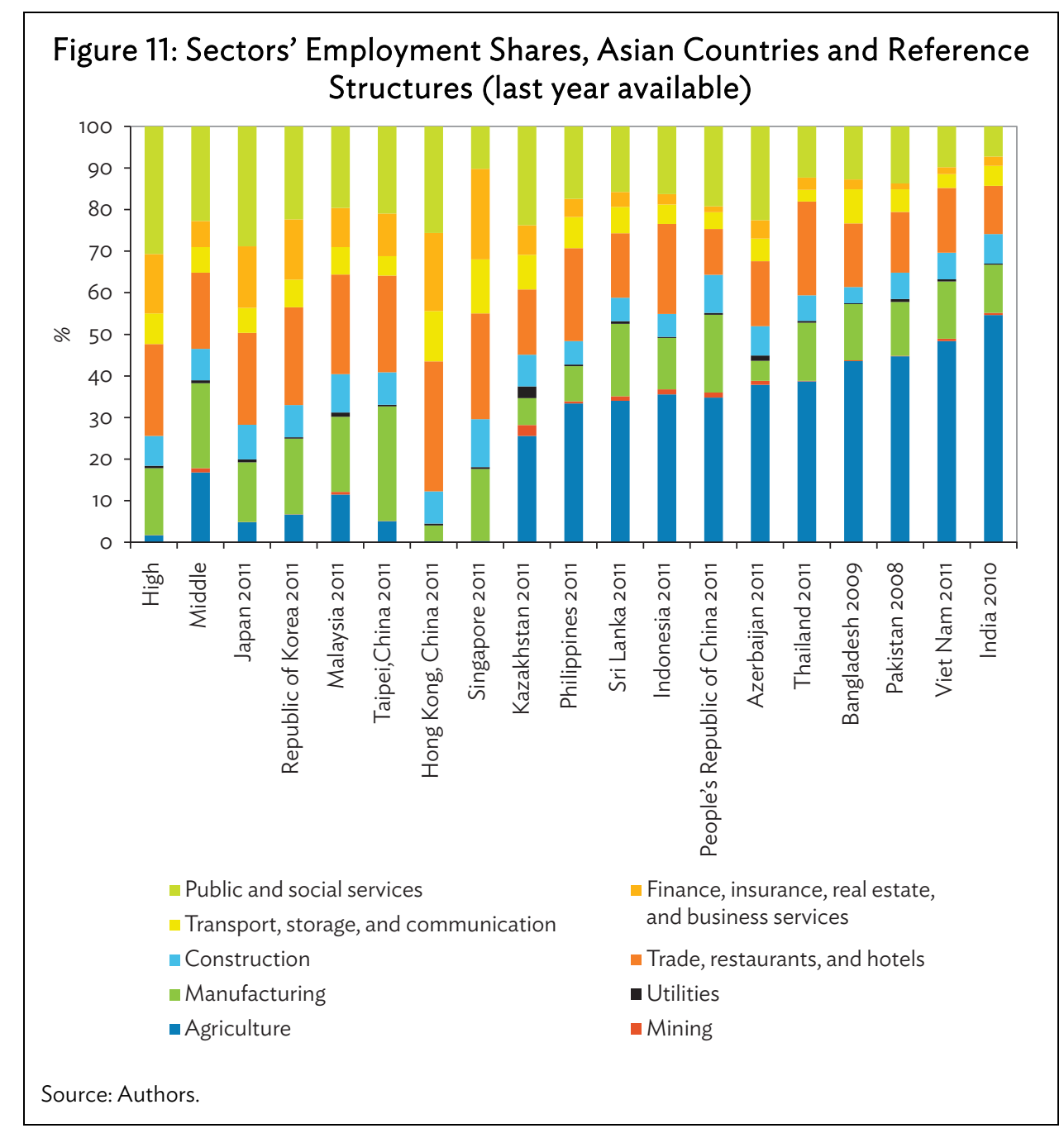

Figure 12 and Figure 13 present the outcome of the counterfactual analysis. The blue bars (labeled $g$ ) present the additional growth, in percentages over the entire period, in the counterfactual scenario (convergence to the employment structure of the reference country) compared to the actual growth pattern of the country, i.e., the difference between the counterfactual and actual. The red bars, labeled $S C$, present the additional structural change that is associated with the counterfactual, relative 
to the actual structural change that the country experienced. ${ }^{7}$ This can be taken as a rough indicator of the effort that would be associated with the counterfactual.

The countries are ranked by the amount of extra structural change that is required in the counterfactual with the high-income level as reference. This is the red bar in Figure 13. India is the country with the highest value for this indicator, meaning that among the countries in the analysis, India is most remote from the typical high-income employment structure. Bangladesh, Thailand, Azerbaijan, Indonesia, the PRC, and the Philippines follow closely. As expected, the high income economies of Asia (Japan; Taipei,China; Republic of Korea; Hong Kong, China; and Singapore) require much less extra structural change to reach the reference employment structure. The relatively low values for Viet Nam, Sri Lanka, and Pakistan are strongly influenced by the fact that we have a shorter period of data for them.

Focusing first on the middle-income reference, Figure 12 shows that India, Pakistan, Bangladesh, and Viet Nam require no extra structural change to reach the middle-income employment structure, but would have nevertheless registered significant extra labor productivity growth (about $8 \%$ per annum). Thailand and the PRC, would also experience significant labor productivity growth (the PRC over 10\% per annum) if their employment structures shifted to that of the middle-income country reference, although both need significant structural change. And as expected, Malaysia and the high-income Asian economies would not gain if their employment structure shifted into that of the middle-income country reference.

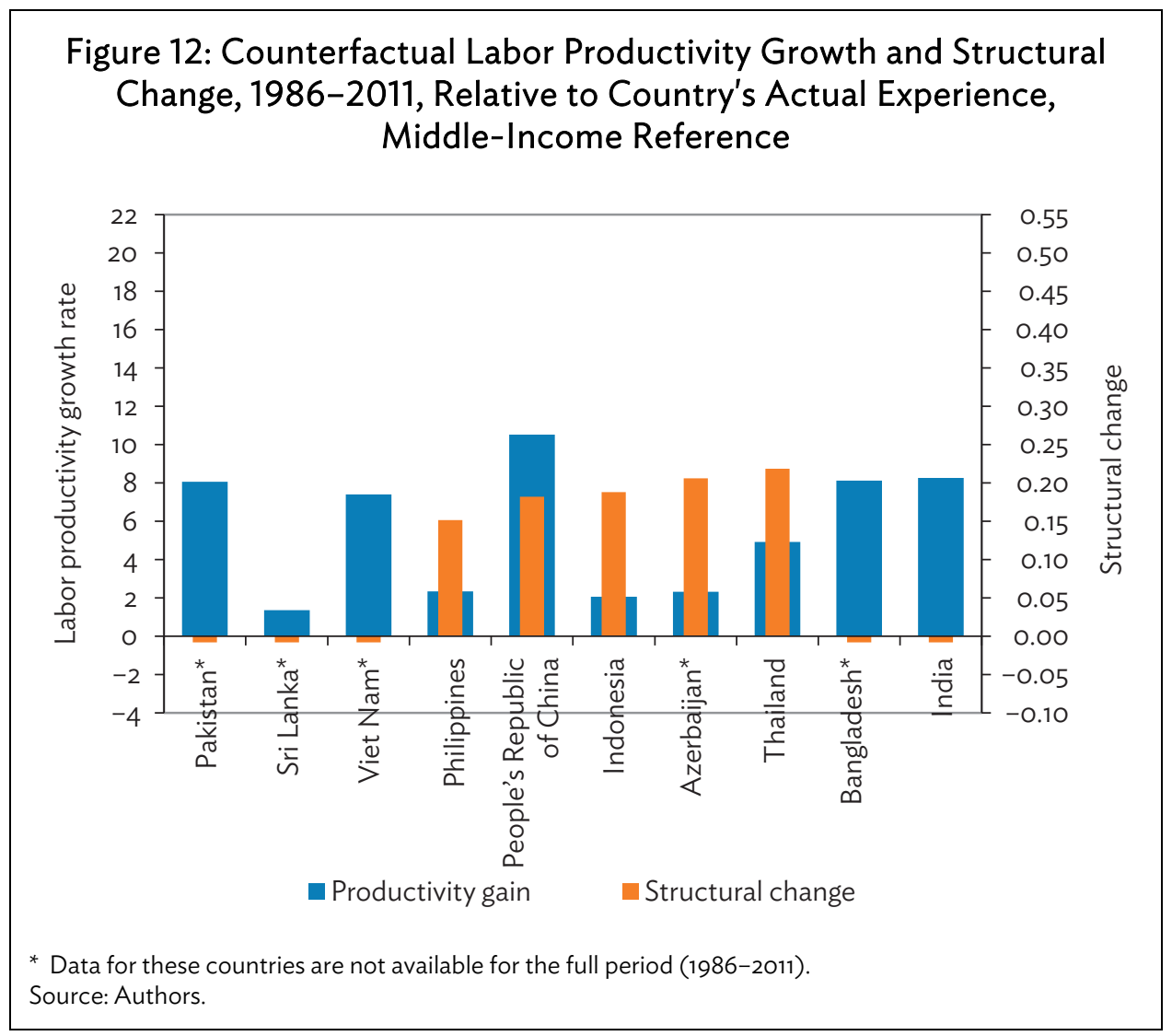

7 Structural change is measured as follows. For the case of actual structural change: $\sum_{i}\left|S_{i}^{1}-S_{i}^{0}\right| / 2$, and for the case of counterfactual structural change: $\sum_{i}\left|S_{i}^{1}-S_{i}^{\prime}\right| / 2$, where $S_{i}^{\prime}$ is the employment share of sector $i$ in the reference country. 
Results are qualitatively similar, but amplified, for the high-income reference (Figure 13). The Philippines, the PRC, Azerbaijan, Thailand, Indonesia, India, and Bangladesh have the highest structural change requirements, meaning that their path to a typical high-income structure is most different from the path that they actually followed. The PRC, Bangladesh, Viet Nam, Pakistan, and India get large labor productivity boosts, especially the PRC (over 20\% per annum). Finally, Azerbaijan stands out with a negative bonus, mostly due to the low role that the mining sector plays in the highincome employment structure.

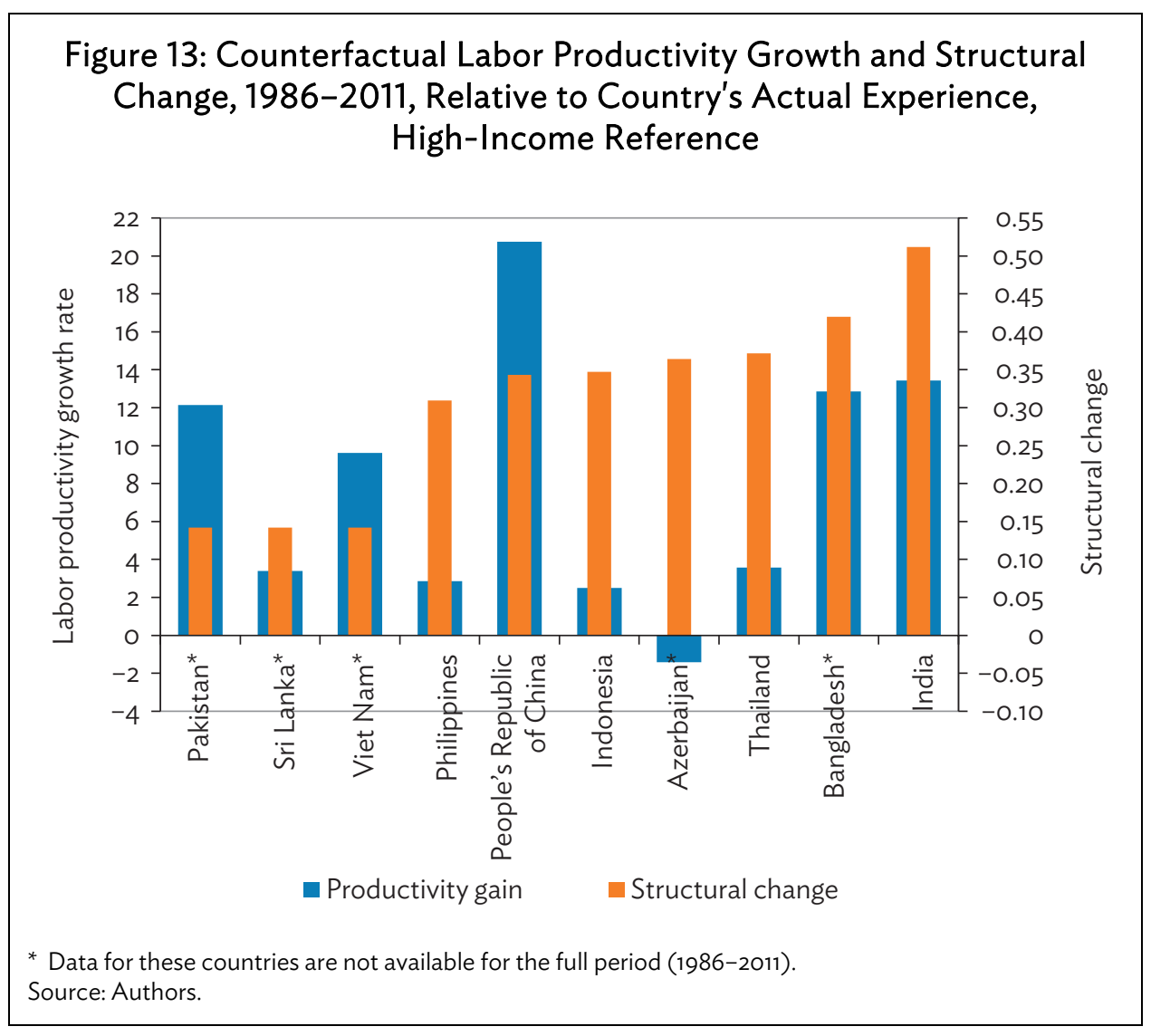

It is important to repeat that these counterfactual analyses are not intended as predictions of what will happen in Asia in the future. They are only rough indications of the order of magnitude of the structural change effect on growth. As such, they are indications that Asia may expect continuing economic growth if it manages to keep using structural change to modernize its economies.

Our analysis has shown that structural change was an important factor in Asian growth in the past decades, with an important vehicle for growth being the reduction in employment's share of agriculture. For the future, it can be expected that market services sectors, such as trade, transport and communication, and FIRBS, will be the vehicle of economic growth, increasingly so when countries progress along the path from middle-income to high-income levels. These services sectors, in particular FIRBS, play an important role in the growth bonuses in the counterfactual analysis. The manufacturing sector also has a positive contribution to the growth bonus in case of the middleincome reference. Services sectors such as FIRBS, and transport and communication also have a positive contribution, but lower than that of manufacturing, mostly because of their smaller share in the middle-income reference. For the high-income reference, these services sectors overtake 
manufacturing, which continues to make a positive contribution however. The public sector has a high weight, but a small contribution in Thailand, both for the middle-income and high-income reference. A common feature in the more detailed results (not documented) of the counterfactual analysis is the fact that the largest part of the negative impact on the growth bonus is taken by the agriculture sector. This sector declines its share greatly in both reference scenarios.

This analysis has shown through hypothetical reallocations of labor from less productive to more productive activities that an economy can grow even if there is no productivity growth within sectors. For the Asian economies considered, labor productivity growth could have been at least $200 \%$ higher during 1986-2011 under the hypothetical employment structures. This type of growthenhancing structural change can be an important contributor to overall economic growth. This is another way of saying that a significant portion of the income gap between rich and poor countries is accounted for by differences in economic structure as opposed to differences in productivity levels within sectors. Therefore, a typical developing economy would get a significant boost if its highproductivity industries employed larger shares of workers.

\section{CONCLUSION AND DISCUSSION}

Structural change and productivity growth are closely intertwined because the broad sectors of the economy offer different possibilities for productivity growth. In particular, the sectors in which more developed countries tend to allocate more labor than developing countries, tend to offer better opportunities for reaching high-productivity levels. The agriculture sector dominates in low-income countries, the manufacturing sector as well as services sector rise in middle-income countries, and the manufacturing share falls in high-income countries, while services rise further.

Our findings are as follows. First, productivity growth within the sector is, in most cases, the largest component of productivity growth in Asia. However, structural effects, especially so the static structural effect that measures the shift of resources into sectors that have high productivity levels at the beginning of our period of analysis, is also a sizable part of productivity growth. The static structural effect is especially strong in countries with intermediate levels of productivity growth (as compared to the general Asian context).

Second, we found that the so-called dynamic structural effect had a negative effect on Asian productivity growth. This effect measures the interaction between the change of the sectoral employment share and the change of productivity in a sector. The negative sign of this effect, in many cases, results from a process of deindustrialization: manufacturing declines in terms of the employment share, but at the same time it shows strong productivity increases.

Third, we found that the structural effects are the most important factor in determining potential productivity growth. The distinction between potential growth and actual growth is important, because there is generally a certain level of "slack" in the economy, which corresponds to the nonuse of a part of potential growth. Our analysis shows that this kind of slack played some role in Asian growth, in particular when related to the labor participation rate, but that this is a relatively minor factor as compared to the structural effects.

Fourth, using more detailed data for a smaller sample of Asian countries, we were able to show that structural change is important both in terms of changes in the extent of capital deepening, and changes in productivity. This implies that structural change plays a large role both in the growth rates 
of labor productivity and total factor productivity. Changes in the extent of capital deepening add to changes in TFP, to make labor productivity growth higher than TFP.

Finally, we find that the nonhigh-income Asian nations in our sample would almost all experience a productivity growth bonus when they would converge to employment structures that are representative for middle- and low-income countries globally. This effect is stronger for the highincome reference than for the middle-income reference. At the same time, most countries also need a fair amount of extra structural change to realize such a convergence. These results illustrate the potential of structural change as a source of productivity growth in Asia. 


\section{REFERENCES}

Chenery, H. B. 1960. Patterns of Industrial Growth. American Economic Review. 50 (4). pp. 624-54.

Kuznets, S. 1971. Economic Growth of Nations: Total Output and Production Structure. Belknap Press of Harvard University Press.

Lanzafame, M., J. Felipe, N. Sotocinal, and C. Bayudan-Dacuycuy. Forthcoming. The Pillars of Potential Growth and the Role of Policy: A Panel Data Approach. ADB Economics Working Paper Series.

McMillan, M., D. Rodrik, and I. Verduzci-Gallo. 2014. Globalization, Structural Change, and Productivity Growth, with an Update on Africa. World Development. 63 (C). pp. 11-32. 


\section{The Role of Structural Transformation in the Potential of Asian Economic Growth}

This paper identifies the pattern of structural change that countries experience as they catch up from lowincome levels to the economic frontier, and examines how structural change contributes to both labor and total factor productivity. Using data for Asian countries the paper goes on to address the extent and form of structural change and its contribution to productivity growth since 1990, asking what order of magnitude the productivity effects are likely to be as Asian countries converge to the economic structure that characterizes middle-income and high-income countries.

\section{About the Asian Development Bank}

ADB's vision is an Asia and Pacific region free of poverty. Its mission is to help its developing member countries reduce poverty and improve the quality of life of their people. Despite the region's many successes, it remains home to the majority of the world's poor. ADB is committed to reducing poverty through inclusive economic growth, environmentally sustainable growth, and regional integration.

Based in Manila, ADB is owned by 67 members, including 48 from the region. Its main instruments for helping its developing member countries are policy dialogue, loans, equity investments, guarantees, grants, and technical assistance. 